\title{
Enhanced Fatigue Strength of Commercially Pure Ti Processed by Rotary Swaging
}

\author{
Hasan ALkhazraji, ${ }^{1}$ Ehab El-Danaf, ${ }^{2}$ Manfred Wollmann, ${ }^{1}$ and Lothar Wagner ${ }^{1}$ \\ ${ }^{1}$ Institute of Materials Science and Engineering, Clausthal University of Technology, 38678 Clausthal-Zellerfeld, Germany \\ ${ }^{2}$ Mechanical Engineering Department, College of Engineering, King Saud University, P.O. Box 800, Riyadh 11421, Saudi Arabia \\ Correspondence should be addressed to Ehab El-Danaf; edanaf@ksu.edu.sa
}

Received 7 October 2014; Revised 19 January 2015; Accepted 20 January 2015

Academic Editor: Luigi Nicolais

Copyright (C) 2015 Hasan ALkhazraji et al. This is an open access article distributed under the Creative Commons Attribution License, which permits unrestricted use, distribution, and reproduction in any medium, provided the original work is properly cited.

Fully reversed bending fatigue tests were performed on polished hour-glass specimens of commercially pure titanium grade 1 with three different grain sizes, that were produced by severe plastic deformation (rotary swaging) and subheat treatments, in order to examine the effect of grain size on fatigue. An improvement in fatigue strength was observed, as the polycrystal grain size was refined. The endurance limit stress was shown to depend on the inverse square root of the grain size as described empirically by a type of Hall-Petch relation. The effect of refining grain size on fatigue crack growth is to increase the number of microstructural barriers to the advancing crack and to reduce the slip length ahead of the crack tip, and thereby lower the crack growth rate. It was found that postdeformation annealing above recrystallization temperature could additionally enhance the work-hardening capability and the ductility of the swaged material, which led to a marked reduction in the fatigue notch sensitivity. At the same time, this reduction was accompanied with a pronounced loss in strength. The high cycle fatigue performance was discussed in detail based on microstructure and mechanical properties.

\section{Introduction}

In conventional fatigue design, the fatigue limit obtained at a number of stress cycles of $10^{7}$ has been used to determine the allowable stress level for design against high cycle fatigue (HCF). However, Fatigue fracture can, still, take place at a number of stress cycles beyond $10^{7}$ cycles even when the stress level is below the conventional fatigue limit, due to stress concentration and other various modifying factors. In recent years, fatigue data obtained for high strength steels have shown anomalous two-stepwise or duplex S-N curves [1-8]. In the HCF regime with life less than $10^{7}$ cycles, fatigue fracture starts from the surface. The fatigue limit of most metallic materials is determined by the propagation condition of nucleated small cracks on the surface. The crack closure and microstructural barriers are two mechanisms for blocking small cracks propagation at the fatigue limit [9].

Fatigue properties are often of primary importance when considering the potential use of bulk ultrafine grained (UFG) materials in structural applications. Some of the earliest investigations of the cyclic behavior of UFG metals were of copper, for example, the experiments by Agnew et al. [10] and their continuation by Mughrabi et al. [11-13]. Various experimental results on the fatigue behavior of UFG metals and alloys are summarized in numerous previous works [1418]. It is established that strength of metals is related inversely to the size of the grain structure as described by the wellknown Hall-Petch (H-P) relationship [19-22]. In the same sense, improved fatigue strength with grain size reduction obtained via equal channel angular pressing of commercial purity aluminium alloy was previously demonstrated [23]. Lukáš et al. [24] have demonstrated the H-P effect for the high cycle fatigue behavior of copper for two grain sizes of 0.3 and $70 \mu \mathrm{m}$.

The H-P relation depends on two constants; one of them represents the friction stress that reflects the overall resistance of the crystal lattice to dislocation movement which is strongly dependent on temperature, strain, and alloy content, and the other represents the relative hardening contribution of the grain boundaries. The H-P equation also 
has been found to apply not only to grain boundaries but to other kinds of boundaries such as ferrite and cementite in pearlite, mechanical twins, and martensite. The original dislocation model for $\mathrm{H}-\mathrm{P}$ equation was based on the concept that grain boundaries act as barriers to dislocation motion [25]. The dislocation pile-up model of Eshelby et al. [26] for the stress concentration produced at the tip of a blocked slip band was employed also by both Hall and Petch to explain the H-P equation. The inverse square root of grain size dependence reported in pioneering researches by Hall and Petch for the yield and cleavage fracture stresses of iron and steel materials demonstrated extension of this grain size dependent relationship to other material properties such as the complete stress strain behavior of diverse metals and alloys, assessments of the ductile-brittle transition, hardness, fatigue, fracture mechanics, shear banding, and strain rate sensitivity properties. The higher Taylor orientation factor $(m)$ of about 6.5 proposed for hcp crystal structure due to the limited orientation dependence of the primary basal slip system until deformation twinning intervenes and, also, the much higher value of the critical resolved shear stress required for the activation of the secondary prismatic or pyramidal slip systems needed to effect accommodation of plastic strains at grain boundaries, compared with the lower value of $m$ of 3.1 for fcc crystal structure, which applies for the multiple available slip systems and the need for cross-slip to occur at grain boundaries for transmission of plastic flow, which are both available to fcc crystal structure; elucidate the higher effect of grain size on strength and consequently strain hardening rate in hcp structures over fcc structures [27]. Besides, Mises [28] has demonstrated the need of five independent operating slip systems, in order to accommodate homogeneous slip, which is generally satisfied in cubic metals and to a much lesser extent in hcp and low symmetry metals [25].

It is relevant to have information also on the fatigue notch sensitivity, because the fatigue performance of notched bodies might be very poor even if the fatigue performance of smooth bodies is good. The stress concentration at a notch is usually described by the geometrical notch factor $k_{t}=$ $\sigma_{\max } / \sigma_{\text {nom }}$ which mainly depends on the notch root radius, the notch depth, and the mode of loading. Experiments have shown that the HCF strength of a notched specimen depends not only on $k_{t}$, but also on materials properties such as microstructure and mechanical properties. Therefore, a fatigue notch factor $K_{f}$ was introduced which relates the smooth HCF strength for a given number of cycles (e.g., $10^{7}$ ) to the notched one $\left(k_{f}=\sigma_{a 10^{7}}\right.$ smooth $/ \sigma_{a 10^{7}}$ notched). $K_{f}$ can be considered as a reduced value of $K_{t}$ and was mainly introduced to take into account the different responses to notches for different materials and different microstructure features. Accordingly, the fatigue notch sensitivity $q$ was developed and expressed as follows [29]:

$$
q=\frac{\left(k_{f}-1\right)}{\left(k_{t}-1\right)} .
$$

Two limiting cases can occur: $q$ equal to 0 (no notch sensitivity) and $q$ equal to 1.0 (full notch sensitive). The first case exists if $\sigma_{a 10^{7}}$ smooth is equal to $\sigma_{a 10^{7}}$ notched and the latter if $k_{f}$ reaches its upper limiting value, which is $k_{t}$. Taking the difference between tensile strength and yield strength (UTS-YS) as a coarse measure for work-hardening capability, it was reported [30] that this difference affects the fatigue notch sensitivity significantly. The higher the difference between tensile strength and yield strength (workhardening capability), the lower the fatigue notch sensitivity and vice versa. It was found that AISI steel 304 was low notch sensitive $(q=0.32)$, while Beta C Titanium was almost fully notch sensitive $(q=0.9)$. The work-hardening capability (UTS-YS) of AISI 304 and Ti-Beta C was 390 and $10 \mathrm{MPa}$, whereas the tensile elongation was $80 \%$ and $20 \%$, respectively.

Rotary swaging is a hammer forming process for the reduction of cross-section of solids, tubes, and wires. The main application is the progressive deformation of circular, concentric reduction. However, the process can also be used in producing other regular forms, for example, hexagonal, octagonal, and square sections. Some of the advantages of rotary swaging include short cycle times, good surface finishes, and tight size tolerances. Swaging is a metal-forming technique in which the metal is plastically deformed to its final shape using high pressure, either by pressing or hammering or by forcing through a die. A schematic sketch of a typical swaging unit is shown in Figure 1 [31]. The main part of the unit consists of a "spindle," with guiding slots which contain the dies (D) and hammer blocks (C). There is a cage containing rollers (B), which itself is contained within the machine retaining chamber $(A)$. When the hammer blocks are between any of the rollers, there is an opening in the dies (Figure 1(a)). As the hammer blocks strike the rollers, the dies close in and exert a blow onto the material. During rotation cycle of the spindle the dies close and open several times depending upon the number of roller cages (B) and the number of dies used (D); for example, in the case of Figure 1, the dies close 12 times in one cycle. The spindle rotates normally at 300-500 rpm, and during each cycle the hammer blocks repeatedly strike the rollers (B). The frequent opening and closing of the dies allow the component to be fed into the swaging machine with little effort from the operator or automatic feeder [32].

In this work, rotating bending fatigue of three-grainsized commercially pure (cp) Ti grade 1 processed by rotary swaging (RS) was conducted on smooth and notched samples. Thermomechanical treatments were applied after rotary swaging to result in a coarse and fine grained material. The evolution of microstructure was investigated via orientation imaging microscopy using electron backscattered diffraction (EBSD). Fatigue performance of various grain sizes is compared and contrasted.

\section{Experimental Procedure}

Commercially pure (CP) $\mathrm{Ti}$ grade 1 was received as hot extruded bar with chemical composition illustrated in Table 1. Round bars were severely plastically deformed (SPD) by rotary swaging (RS) at ambient temperature from $\varnothing$ $($ diameter $)=32 \mathrm{~mm}$ down to $\varnothing=9 \mathrm{~mm}$ in multiple 


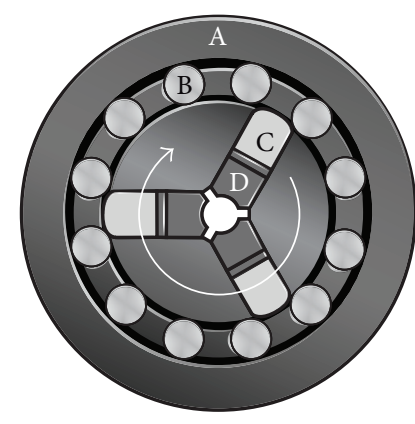

(a)

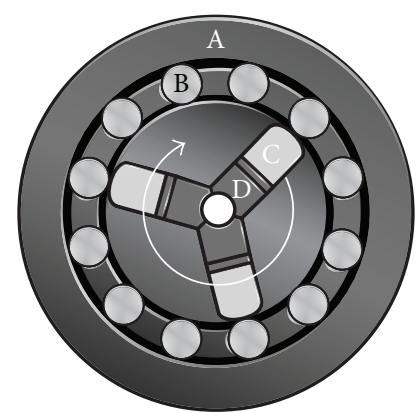

(b)

Figure 1: Swaging tool (schematic) in (a) opening of dies and in (b) closure of dies [31].

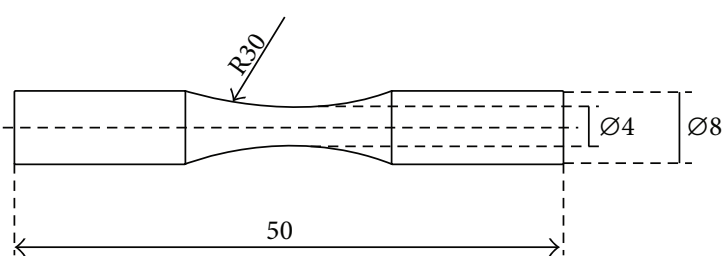

(a) Smooth

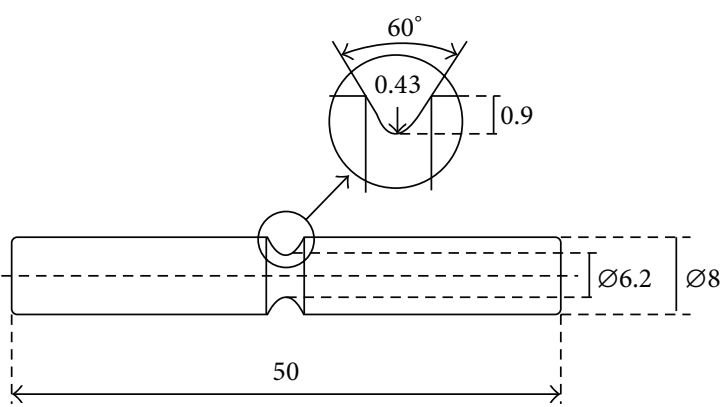

(b) Notched

Figure 2: Geometry of the fatigue specimens.

TABLE 1: Chemical composition of CP-Ti grade 1, wt\%.

\begin{tabular}{lcccccc}
\hline Element & $\mathrm{N}$ & $\mathrm{H}$ & $\mathrm{C}$ & $\mathrm{Fe}$ & $\mathrm{O}$ & $\mathrm{Ti}$ \\
\hline CP-Ti & 0.015 & 0.0018 & 0.009 & 0.04 & 0.0613 & Rest \\
\hline
\end{tabular}

steps, which corresponded to a true strain of 2.5 (true strain calculated from cross-section area reduction). The severely plastically deformed material was then either recrystallization annealed at $850^{\circ} \mathrm{C}$ for 24 hours to result in a coarse grained microstructure and annealed at only $450^{\circ} \mathrm{C}$ for 1 hour to produce a fine grained counterpart. Tensile tests (initial strain rates $6.7 \times 10^{-4} \mathrm{~s}^{-1}$ ) were performed using threaded cylindrical specimens having gage lengths and gage diameters of 25 and $5 \mathrm{~mm}$, respectively. In addition, hardness tests were performed on the swaged material after annealing at various temperatures for $1 \mathrm{~h}$.

HCF tests were conducted in rotating beam bending $(R=$ $-1)$ on hour-glass shaped smooth $\left(k_{t}=1.0\right)$ specimens and notched $\left(k_{t}=2.0\right)$ specimens. Both specimen types were ground and electrolytically polished to eliminate the existence of surface cracks. The hour-glass shaped specimens had a minimum diameter of $4 \mathrm{~mm}$. The notched specimens with a minimum diameter of $6.2 \mathrm{~mm}$ had a notch depth of $0.9 \mathrm{~mm}$, a notch angle of $60^{\circ}$, and a notch root radius of $0.43 \mathrm{~mm}$, which corresponded to a value of $k_{t}$ of 2.0 , as shown in (Figure 2).

Worth mentioning is that the range of $k_{t}$ values, in general, is related to the difference in the samples minimum
TABLE 2: Details of thermomechanical treatments of CP-Ti grade 1.

\begin{tabular}{lc}
\hline Condition & Thermomechanical treatment \\
\hline Ultrafine grain (UFG) & Swaged $(\mathrm{SW})$ \\
Fine grain (FG) & $\mathrm{SW}+450^{\circ} \mathrm{C}$ for $1 \mathrm{~h}$ \\
Coarse grain (CG) & $\mathrm{SW}+850^{\circ} \mathrm{C}$ for $24 \mathrm{~h}$ \\
\hline
\end{tabular}

diameter and notch depths obtained after machining. These differences become more significant after electropolishing of the samples, as the removed surface layers are not almost constant in all samples. Test frequency was about $50 \mathrm{~Hz}$. Three conditions were investigated in this study, related to three different grain sizes obtained through thermomechanical treatments summarized in Table 2. The microstructure of the three conditions was characterized normal to the extrusion direction by electron backscattered diffraction (EBSD) using Oxford HKL system incorporated on a field emission scanning electron microscope (FESEM) 7600 JEOL. Sectioned samples were ground up to 4000 grit, polished by alumina, and further polished on a vibratory polisher for 2 hours using $0.06 \mu \mathrm{m}$ colloidal silica.

\section{Results and Discussion}

3.1. Microstructure of CP-Ti Alloy. The microstructure of the material in the three processed conditions was characterized by EBSD and revealed the grain structure details given in 


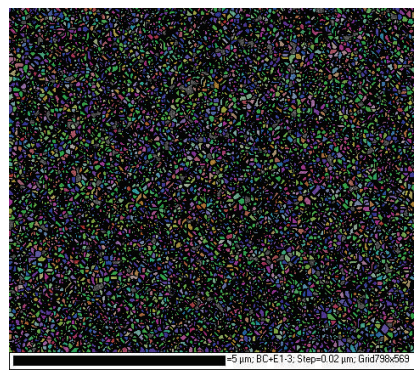

(a)

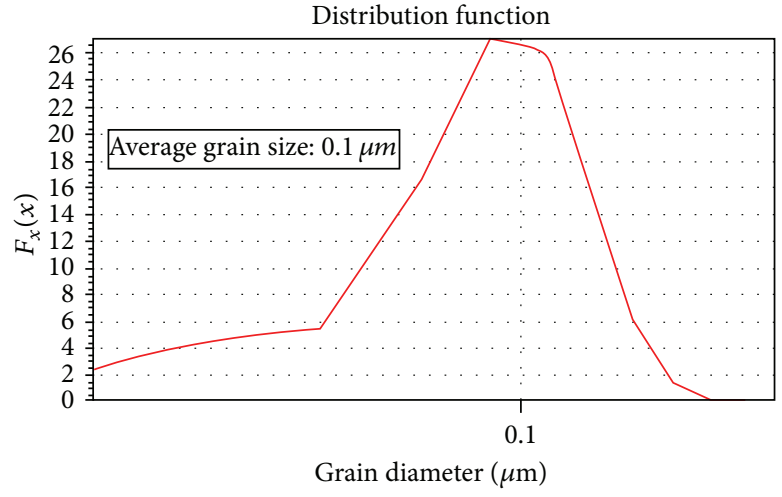

(b)

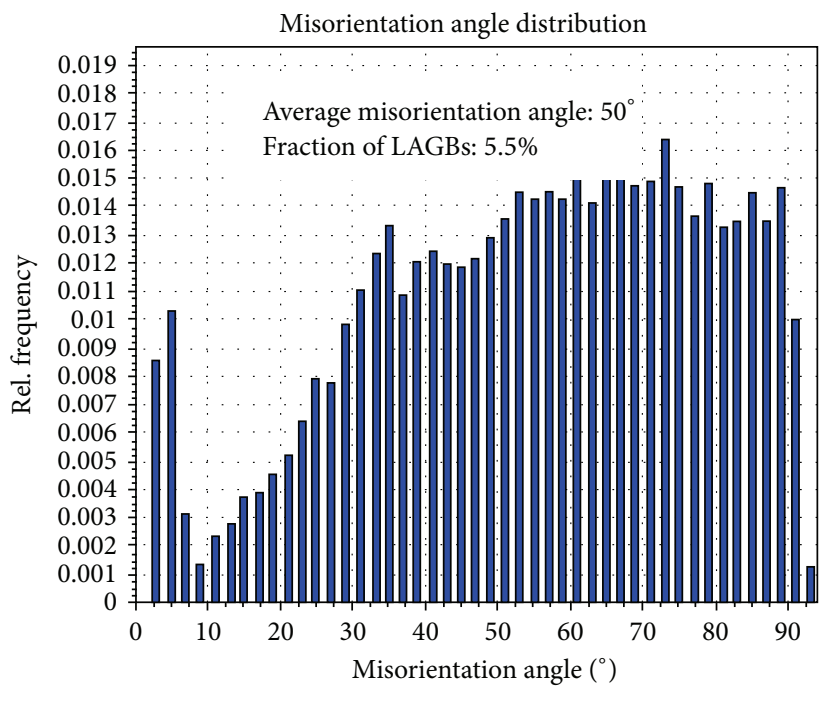

口 Correlated (90783)

(c)

Figure 3: Color coded grain map in (a), grain size distribution in (b), and histogram for the variation of misorientation angle in (c) for the RS condition.

Figures 3-5. It was concluded from preliminary scans that the grain size is too fine for the swaged and swaged + annealed at $450^{\circ} \mathrm{C}$ conditions; for that reason a scan step of $0.02 \mu \mathrm{m}$ and $0.05 \mu \mathrm{m}$ was implemented in these two samples, respectively. Figure 3 is for the as-swaged condition giving the euler coded map in (a), distribution and variation of grain size with critical misorientation angle of $10^{\circ}$ in (b), and histogram for the variation of misorientation angle plotted with a bin of $2^{\circ}$ in (c). It is seen that the average grain size, based on the $10^{\circ}$ critical misorientation, is about $0.1 \mu \mathrm{m}$, the average misorientation angle is about $50^{\circ}$, and the fraction of low angle grain boundaries (LAGBs) is about $6 \%$. These values point towards the fact that the majority of grains are bounded by true high angle boundaries. Annealing the swaged sample at $450^{\circ} \mathrm{C}$ for $1 \mathrm{~h}$ has not changed the grain structure significantly as shown in Figure 4 . The average grain size has relatively increased to $0.36 \mu \mathrm{m}$; the average misorientation angle has marginally increased to $55^{\circ}$ with almost the same fraction of LAGBs of $6 \%$. However, on the other hand, the $24 \mathrm{~h}$ annealing at $850^{\circ} \mathrm{C}$ has changed the microstructure significantly. The grain size has increased to about $90 \mu \mathrm{m}$, with average misorientation angle of $49^{\circ}$ with relatively higher fraction of LAGBs of $12 \%$, as illustrated in Figure 5.

The microstructure details show the similarity exhibited by $\mathrm{SW}$ and $\mathrm{SW}+$ annealed at $450^{\circ} \mathrm{C}$ for $1 \mathrm{~h}$, which indicate the thermal stability of the processed microstructure for this annealing condition; however this stability is rather lost for the other annealing condition. The microstructures of fine and coarse grains are generated by annealing the swaged materials above the recrystallization temperature to generate different grain sizes.

It is concluded from the equiaxed structure, observed in all EBSD maps, that the structure is completely recrystallized. It is believed that the severe plastic deformation via cold swaging has induced full dynamic recrystallization. The other two grain sizes were achieved by isothermal annealing which involves static recrystallization. In all cases, 


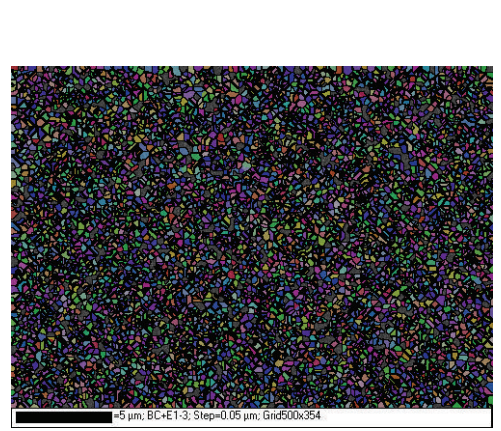

(a)

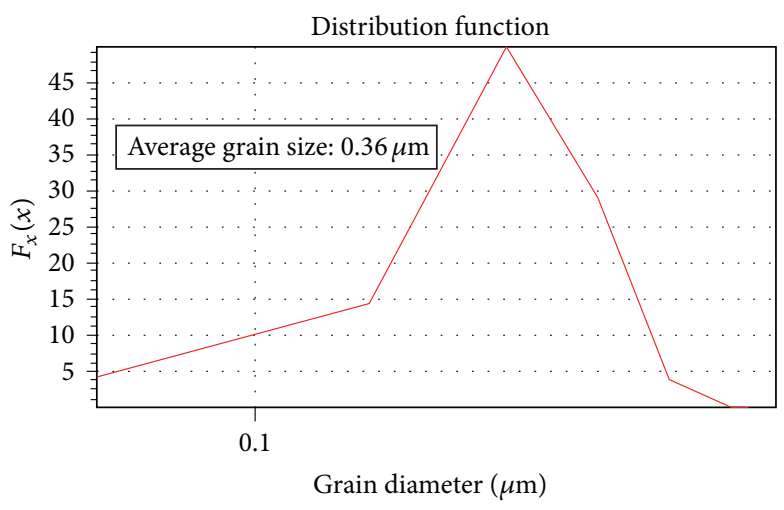

(b)

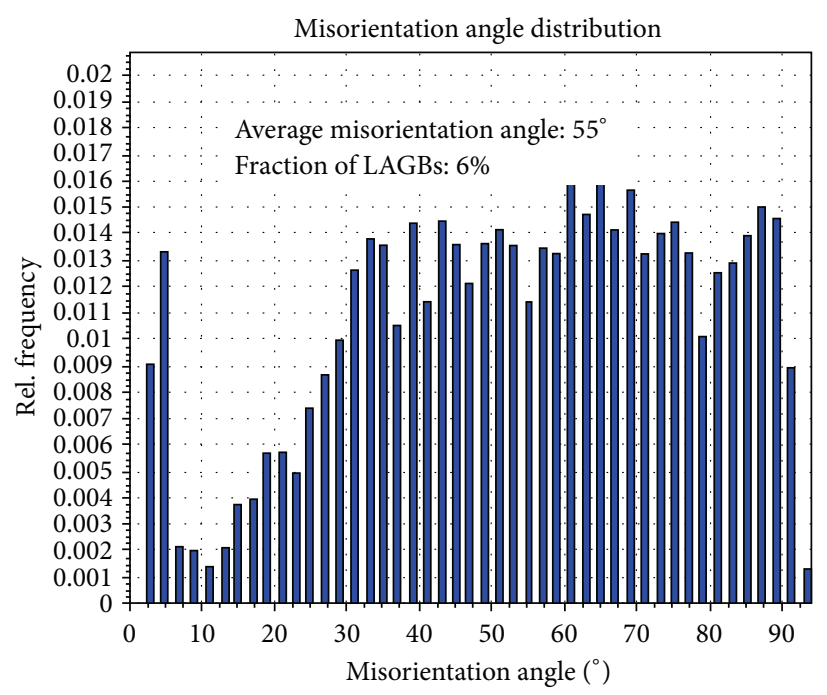

- Correlated (26212)

(c)

Figure 4: Color coded grain map in (a), grain size distribution in (b), and histogram for the variation of misorientation angle in (c) for the $\mathrm{RS}$ and annealing at $450^{\circ} \mathrm{C}$ for $1 \mathrm{~h}$ condition.

the grain boundaries seem to be well developed into true high angle grain boundaries by absorbing the large number of dislocations developed by cold deformation. Comparable severe plastic deformation techniques such as ECAP [33], friction stir processing [34], and high pressure torsion [35] of aluminum alloys have demonstrated a microstructure with a fraction of high angle boundaries of more than $75 \%$. Swaging of commercially pure aluminum at room temperature, to a reasonably similar true strain to the one currently experienced on titanium, yielded a grain size of about $0.7 \mu \mathrm{m} \mathrm{[36].}$ Similarly, swaging was conducted at $850^{\circ} \mathrm{C}$ on Ti54 M to a similar strain level and yielded a grain size of about $1.5 \mu \mathrm{m}$, which after isothermal annealing for $1 \mathrm{hr}$ at $450^{\circ} \mathrm{C}$ followed by air cooling and at $850^{\circ} \mathrm{C}$ followed by furnace cooling, yielded a grain size of $1.5 \mu \mathrm{m}$ and $5 \mu \mathrm{m}$, respectively. With annealing, the fraction of HAGBs approached almost $80 \%$ [37].

3.2. Tensile Strength and Hardness. Figure 6 shows the engineering stress strain response of the investigated materials, for the three grain sizes, under tensile loading. It is obvious that UFG material has superior strength in comparison to the fine grained (FG) and coarse grained (CG) materials. At the same time, the ductility (tensile elongation percent to fracture) and uniform strain of UFG are much less. The mechanical properties inferred from the tensile tests along with the Vickers hardness are summarized in Table 3. As seen, the work-hardening capability (UTS-YS) of FG and CG materials is markedly higher than that of UFG material. It is clearly seen that UFG has superior mechanical strength values over FG and CG conditions and much less elongation percent. The relative losses in yield strength, tensile strength, and hardness values between the UFG and FG conditions are $33 \%, 19 \%$, and $24 \%$, respectively. The relative loss, in the same properties, between UFG and CG is much more significant and the values are $74 \%, 50 \%$, and $33 \%$, respectively.

3.3. Isothermal Annealing. The effect of the annealing temperature for $1 \mathrm{~h}$ on YS, UTS, and elongation to failure $\left(\varepsilon_{F}\right)$ 


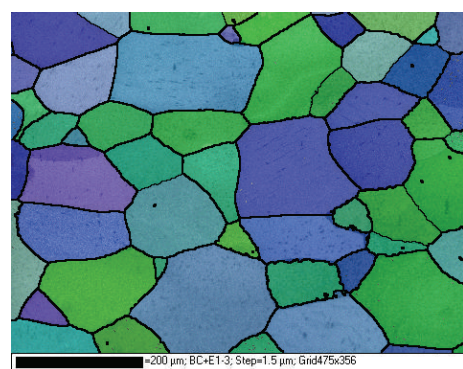

(a)

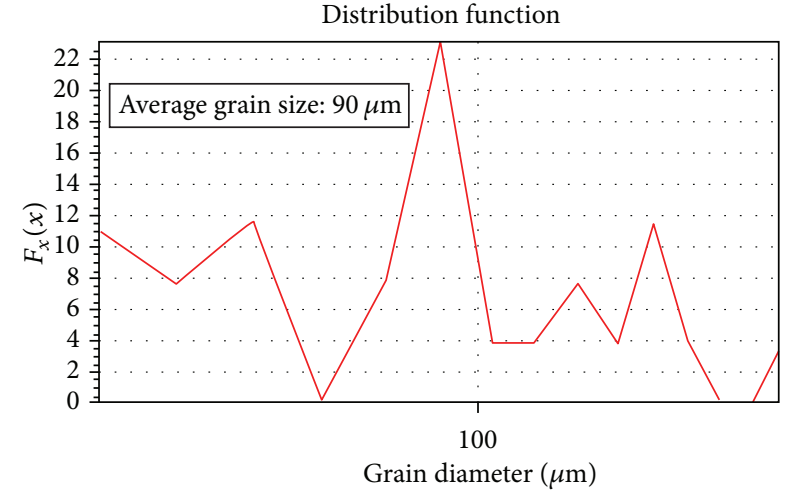

(b)

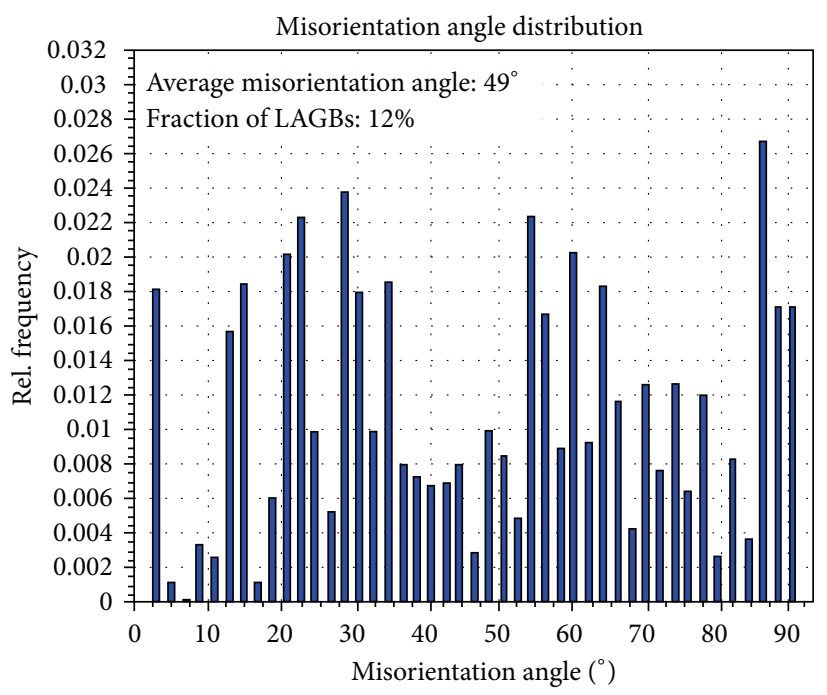

- Correlated $(7100)$

(c)

Figure 5: Color coded grain map in (a), grain size distribution in (b), and histogram for the variation of misorientation angle in (c) for the $\mathrm{RS}$ and annealing at $850^{\circ} \mathrm{C}$ for $24 \mathrm{~h}$ condition.

TABLE 3: Tensile and hardness properties of CP-Ti grade 1 in various conditions.

\begin{tabular}{|c|c|c|c|c|c|}
\hline Condition & YS (MPa) & UTS (MPa) & UTS-YS (MPa) & EI (\%) & HV10 \\
\hline Ultrafine grain (UFG) & 875 & 920 & 45 & 11 & 236 \\
\hline Fine grain $(\mathrm{FG})$ & 585 & 745 & 160 & 18 & 178 \\
\hline Coarse grain (CG) & 155 & 370 & 215 & 57 & 118 \\
\hline
\end{tabular}

on the rotary swaged material is illustrated in Figure 7. YS as well as UTS gradually decreases with an increase in annealing temperature. As the strength values decrease, the tensile ductility markedly increases. With an increase in annealing temperature, the difference between UTS and YS clearly increases amounting to $215 \mathrm{MPa}$ at the highest annealing temperature of $850^{\circ} \mathrm{C}$ (Figure 7). However, the difference between UTS and YS was only $44 \mathrm{MPa}$ at ambient temperature (SW condition).

Figure 8 represents the variation of hardness of the swaged material after being subjected to $1 \mathrm{~h}$ annealing at different temperatures. It can be seen that the as-swaged condition exhibits a marked loss in hardness after annealing at temperatures greater than $600^{\circ} \mathrm{C}$.

3.4. High Cycle Fatigue (HCF). The S-N curves of UFG, FG, and $\mathrm{CG}$ materials in both smooth and notched conditions are depicted in Figures 9 and 10. Figure 9 shows the fatigue performance of the smooth samples of UFG, FG, and CG materials. It is clear that the fatigue strength at $10^{7}$ cycles decreases in the sequence of UFG to FG to CG material. The fatigue strength of UFG and FG is significantly higher than that of the CG material. The fatigue limit of UFG and FG material is about 525 and $425 \mathrm{MPa}$, respectively, which are 


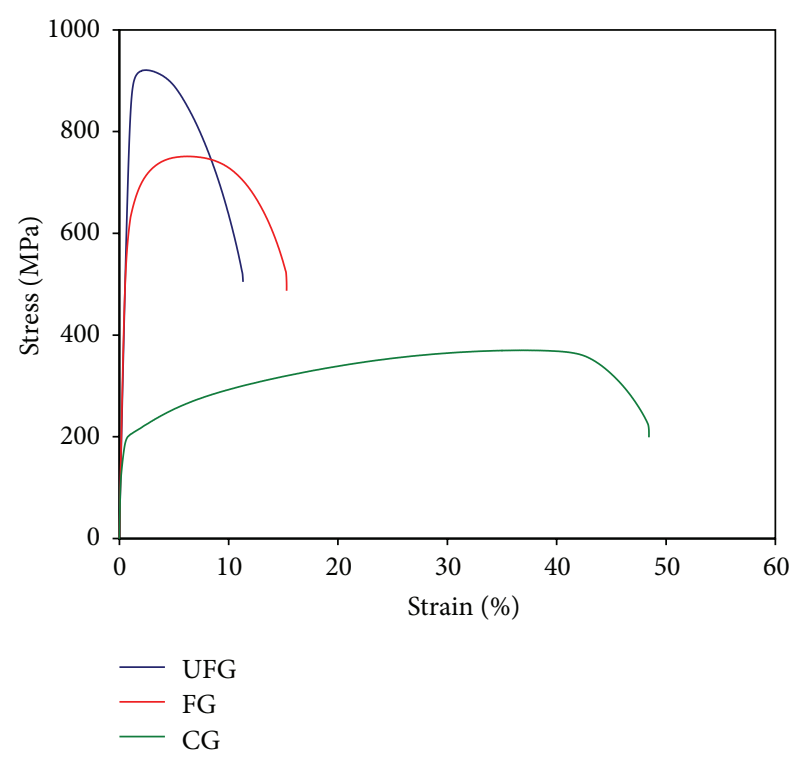

FIGURE 6: Engineering stress strain curve of different conditions.

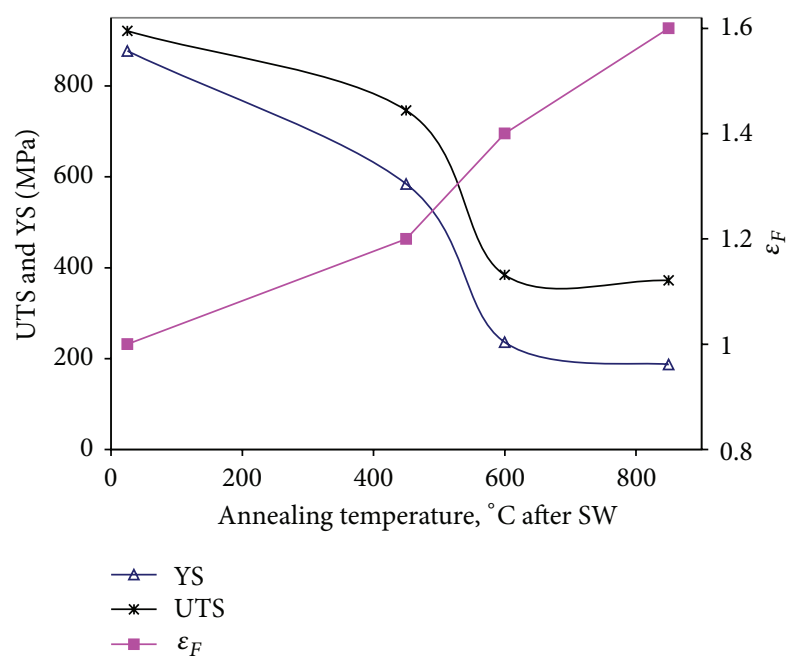

FIGURE 7: The effect of different annealing treatment on yield strength, ultimate strength, and ductility.

much higher than that of CG material that exhibits a value of $120 \mathrm{MPa}$. This may be attributed to the much smaller grain size exhibited for the UFG and FG materials [38]. Figures 10 (a) -10 (c) represent the fatigue performance of UFG, FG, and CG materials, respectively, in both smooth and notched conditions. In each plot, the fatigue performance of the notched sample after being magnified with the value of $k_{t}$ (2.0) was also plotted for comparison. It should be noted that this is done with the assumption that $k_{f}$ has reached its upper limiting value $\left(k_{t}\right)$, where the state of full notch sensitivity is reached. The fatigue results of all tested materials together with the calculated $k_{f}$ and $q$ values are listed in Table 4. For the UFG material the calculated value of $\sigma_{a 10^{7}}$ smooth $/ \sigma_{a 10^{7}}$ notched, which corresponds to the value of $k_{f}$, is 2.0. This calculated value of $k_{f}$ is the same as $k_{t}$ which

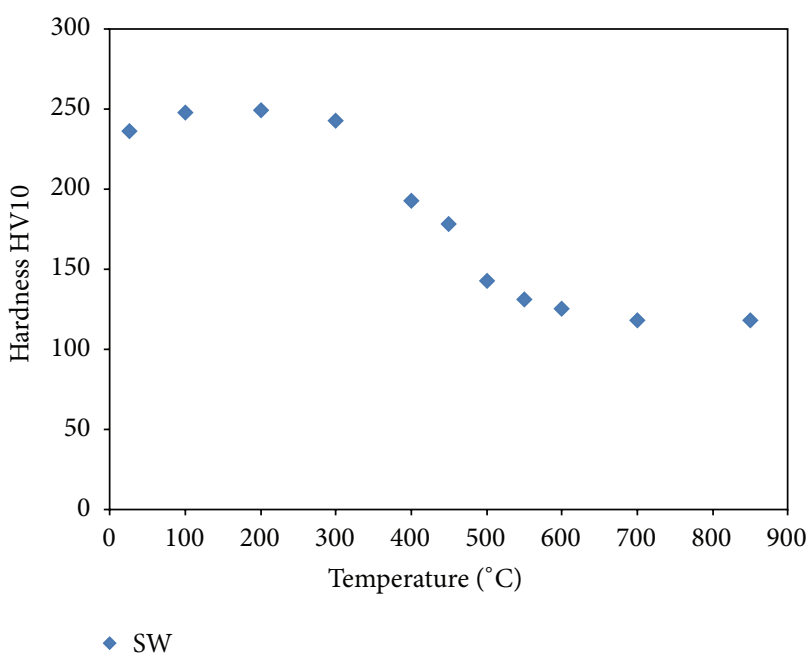

FIGURE 8: Hardness as a function of temperature for swaged conditions.

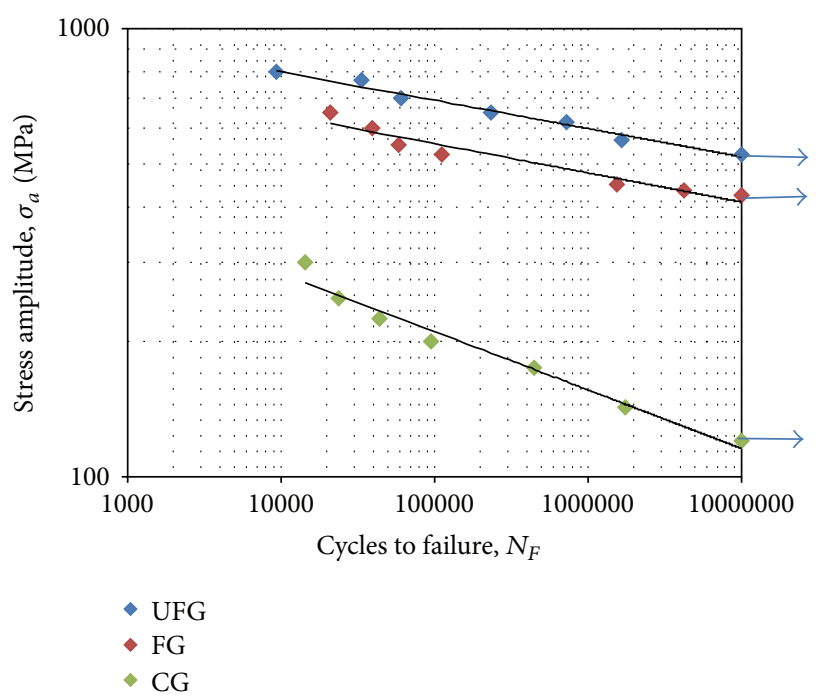

FIGURE 9: S-N curves of smooth samples in rotating beam loading $(R=-1)$.

confirms a state of full notch sensitivity $(q=100 \%)$. However, the HCF performance of FG and CG materials is only slightly deteriorated by the notch ( $q=86$ and $41 \%$, resp.). UFG materials processed by SPD usually have higher fatigue notch sensitivity than their coarse grained counterparts; this was reported for UFG copper [39] and UFG Ti [40]. Pervious study on the fatigue and fatigue notch sensitivity of UFG Ti [41] showed that postdeformation annealing could enhance the materials ductility and lower fatigue notch sensitivity.

Figure 11 shows that the higher work-hardening capability and ductility, the lower fatigue notch sensitivity. Pervious study on pure titanium [41] showed that the ductility can considerably influence the fatigue notch sensitivity of ultrafine grained material. The increase of the static strength can enhance the material resistance to crack nucleation, but at the same time, the fatigue life of samples is defined 


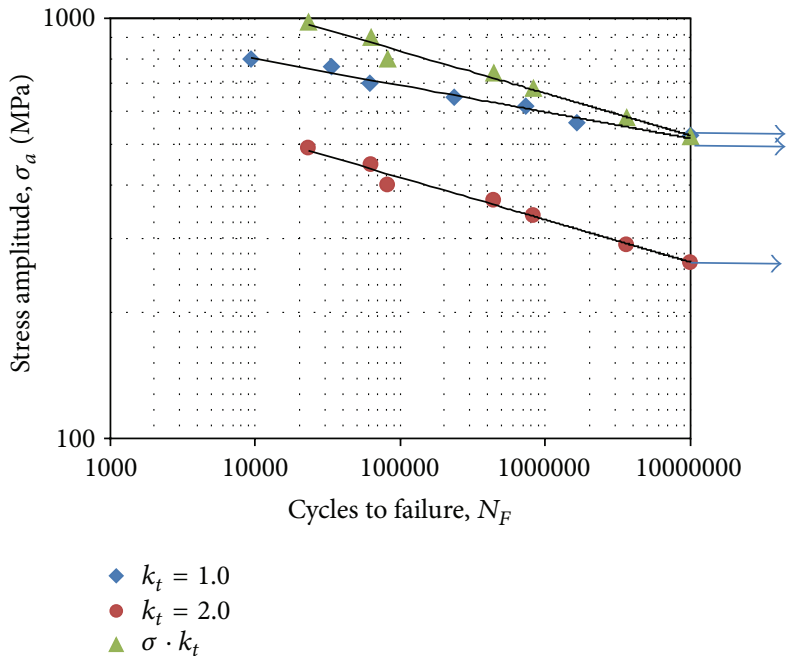

(a)

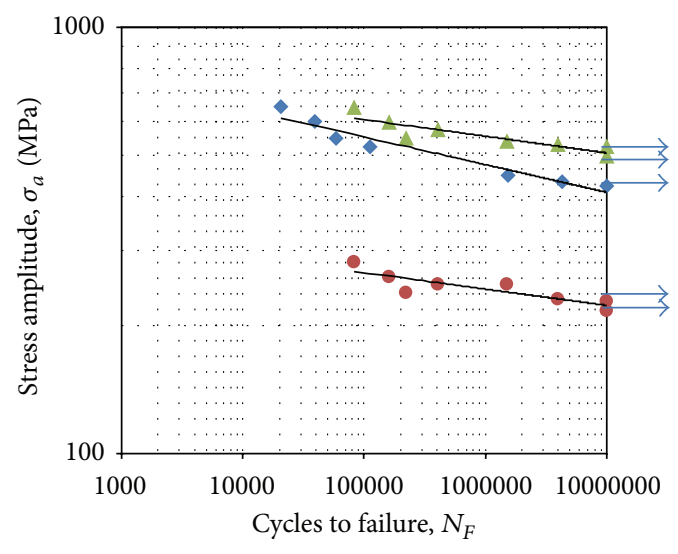

$-k_{t}=1.0$

- $k_{t}=2.0$

$\Delta \sigma_{a} \cdot k_{t}$

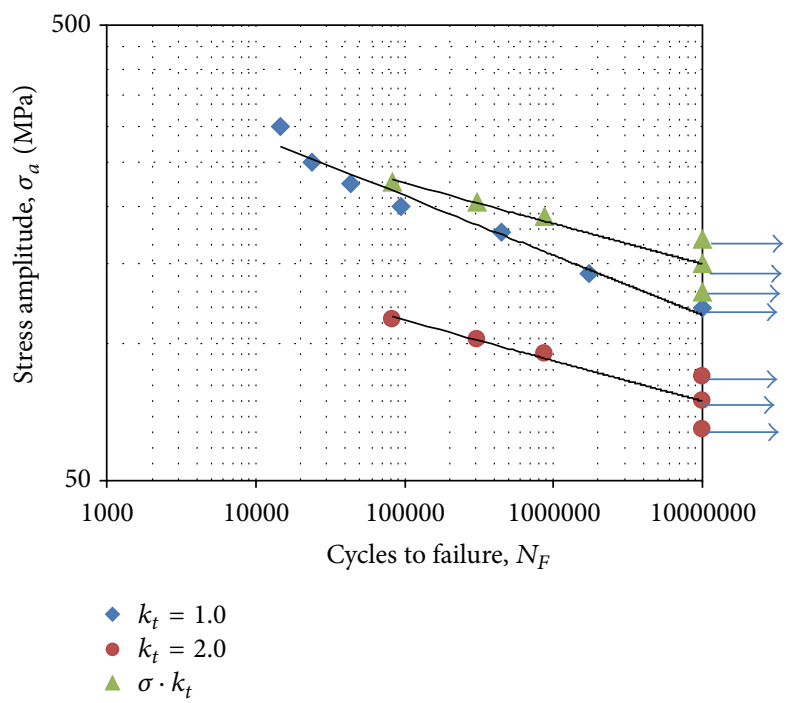

(c)

FIGURE 10: S-N curves of smooth and notched samples in rotating beam loading ( $R=-1$ ): (a) UFG condition, (b) FG condition, and (c) CG condition (rhombus symbol is for the smooth sample, solid circle is for the notched sample, and triangle symbol is for the data of notched sample multiplied by $k_{t}$ ).

TABLE 4: Fatigue performance of the various conditions.

\begin{tabular}{|c|c|c|c|c|c|c|c|}
\hline \multirow{2}{*}{ Condition } & \multirow{2}{*}{$\begin{array}{c}\sigma_{a 10^{7}} \\
\text { Smooth }(\mathrm{MPa})\end{array}$} & \multirow{2}{*}{$\begin{array}{c}\sigma_{a 10^{7}} \\
\text { Notch }(\mathrm{MPa})\end{array}$} & \multicolumn{2}{|c|}{$\left(\sigma_{a 10^{7}} / \mathrm{YS}\right)$} & \multirow{2}{*}{$K_{t}$} & \multirow{2}{*}{$K_{f}$} & \multirow{2}{*}{$q(\%)$} \\
\hline & & & Smooth & Notch & & & \\
\hline UFG & 525 & 262 & 0.60 & 0.30 & 2.0 & 2.0 & 100 \\
\hline FG & 425 & 228 & 0.73 & 0.39 & 2.0 & 1.86 & 86 \\
\hline CG & 120 & 85 & 0.77 & 0.55 & 2.0 & 1.41 & 41 \\
\hline
\end{tabular}

by their crack propagation resistance and can depend on the material ductility [42]. For CG and FG materials, the ratio of the fatigue strength to the yield strength $\left(\sigma_{a 10^{7}} / \mathrm{YS}\right)$ is the highest for both smooth and notched conditions (Table 4), while for UFG materials it approximately equals 0.60 and 0.30 for smooth and notched samples, respectively. This low ratio of UFG material is attributed to its limited ductility in cyclic deformation, which promotes early crack initiation. The fatigue life in HCF regime is controlled by crack nucleation in a smooth body, where crack propagation is often dominating in the LCF regime $[43,44]$. Moreover, in HCF regime, the cyclic loading of UFG materials yields coarse grains at lower stresses, thereby providing a natural pathway for early strain localisation and premature failure either due 


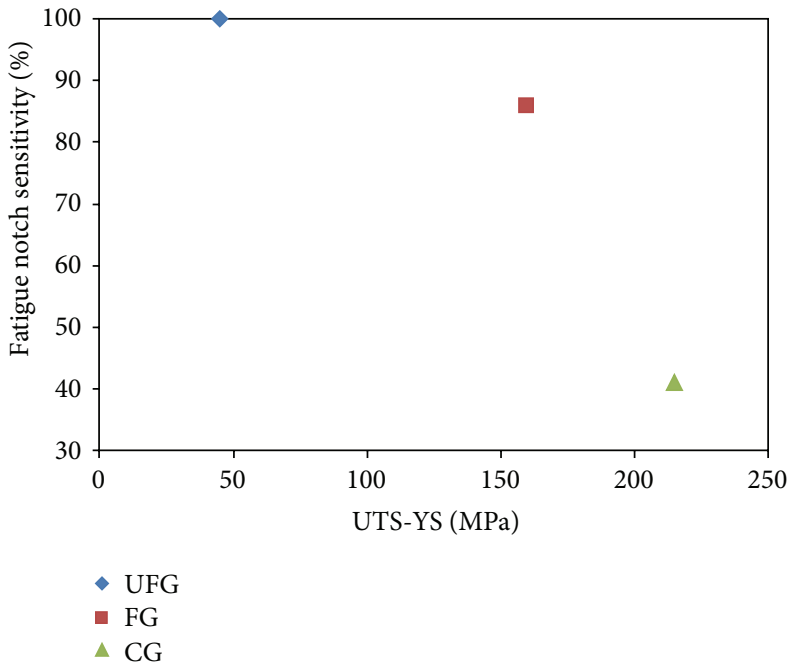

(a)

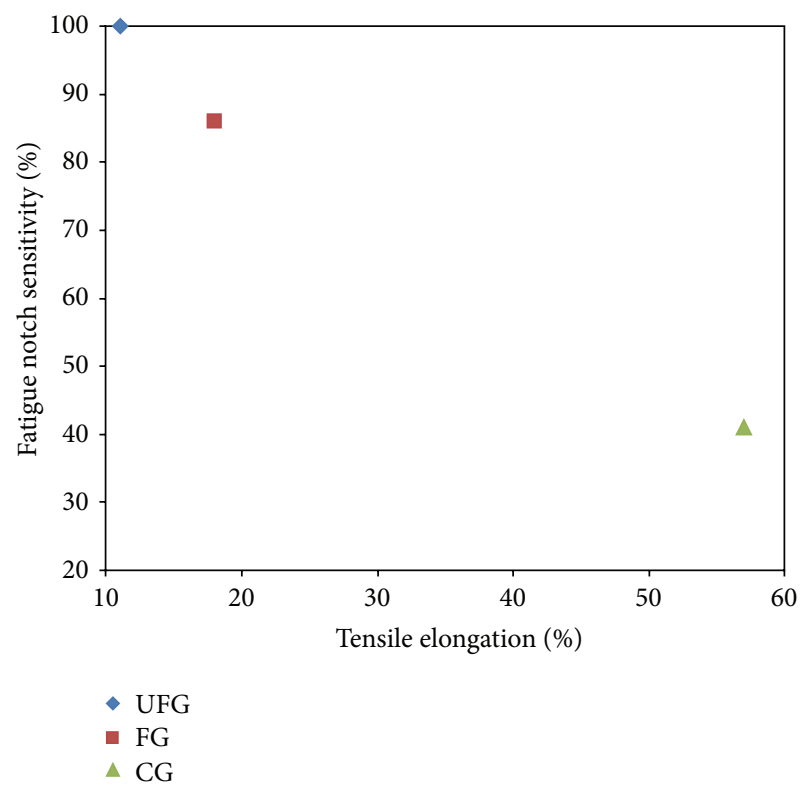

(b)

FIGURE 11: Fatigue notch sensitivity $(q)$ against (UTS-YS) difference in (a) and tensile elongation in (b).

to cracking at the interfaces between the coarse grains and the surrounding fine grain matrix or due to transgranular surface crack initiation in a coarse shear band [45]. The occurrence of large scale shear bands associated with UFG processing is a crucial factor in the fatigue life. Previous work on cold rolling of a group of face center cubic (FCC) alloys revealed that the existence of macroscale shear bands was promoted by finer initial grain sizes [46]. Fatigue cracks most often initiate at and propagate along these shear bands, which can extend over a large number of ultrafine grains or even propagate across a whole specimen [44]. It was reported that the crack growth rate in the near-threshold region is higher in the UFG state than in the ordinary CG materials; however, the picture might be opposite for relatively high stress intensities. Compared to CG material, stable fatigue cracks in the UFG specimens propagate with much less out-of-plane deflections, providing faster fatigue crack growth rates at low stress intensities [47]. Surface intrusions/extrusions associated with cyclic stresses produce dislocation dipoles. The closer stress dependence on distance of such dipoles has been associated with a greater number of dislocations being squeezed into a persistent slip band whose intrusion/extrusion behavior leads to cracking [48]. Fatigue cracking in the ultrafine grain size material was observed just underneath the observation of highly localized surface extrusions/intrusions. A mechanism was proposed of dislocation interactions producing atomic vacancies which then migrate along grain boundaries to form cracks [27].

In the present study, it is shown that enhancement of UFG work-hardening capability and ductility by annealing can considerably reduce the fatigue notch sensitivity. However, this reduction is accompanied by loss in fatigue strength. The necessity arises for other SPD methods that ensure suitable ductility for the material besides high strength, especially under stress concentrator condition. Therefore, work-hardening capability and ductility are essential factors for designing components, where notches are encountered in service.

Figures 12(a)-12(c) present the stereo-images for the CG, FG, and UFG conditions, respectively, for low stress amplitude $\left(\sim 2 .(10)^{6}\right.$ cycles). The common finding for all conditions is that the fracture surface is dominated with flat cleavage transgranular facets and microcracks, indicating brittle fracture. For the CG sample, signs of limited dimple areas attributed to limited microplasticity can be observed, which can give rise to a mixed mode of ductile-brittle fracture, though more inclined towards the brittle mode. The size of the cleavage facets is related to the predeformed grain size, where fine facets associated with small grain size can be noticed in Figures 12(b) and 12(c). Recent TEM studies on UFG copper [42] under high and low stress amplitudes in HCF region have suggested that limited dislocation activities were observed at low stress amplitude and almost no plasticity is induced leading to cleavage-brittle fracture. On the other hand, at high stress amplitude, motion of dislocations becomes large enough that enhances microplasticity and leads to formation of dislocation walls, cells, and large scale shear bands. This enhanced microplasticity leads to ductilebrittle fracture mode at high stress amplitudes.

3.5. Hall-Petch Relation. The effect of polycrystal grain size on the yield strength and endurance stress corresponding to $N=10^{7}$ load cycles is shown in Figure 13. Figure 13 shows that the endurance stress is dependent on the inverse square root of grain size, $d^{-1 / 2}$, and can be described by a type of Hall-Petch type relation $[49,50]$. Similar grain size dependence describes yielding under both monotonic and 


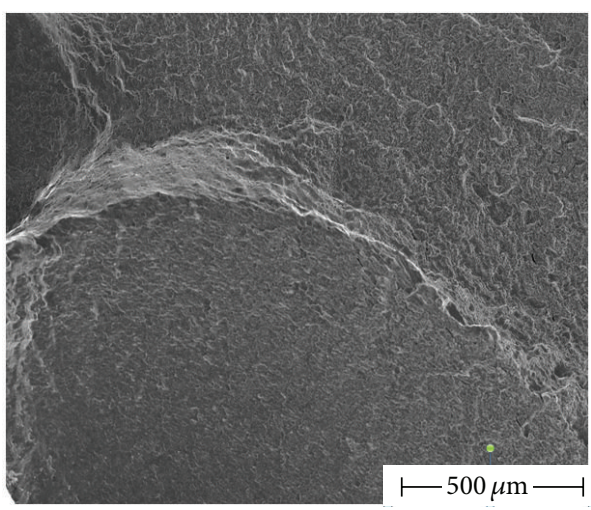

(a)

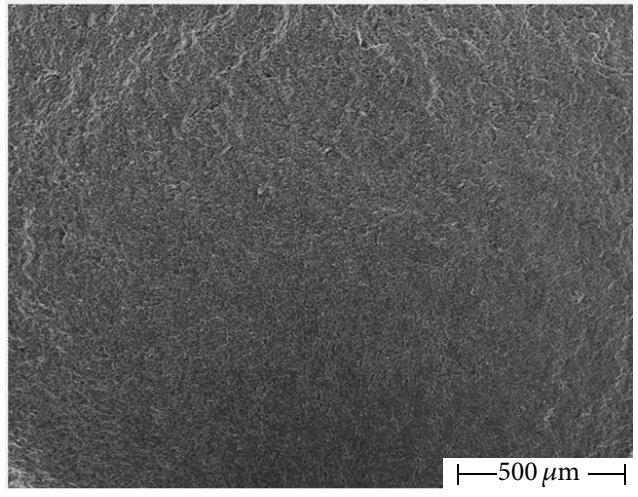

(b)

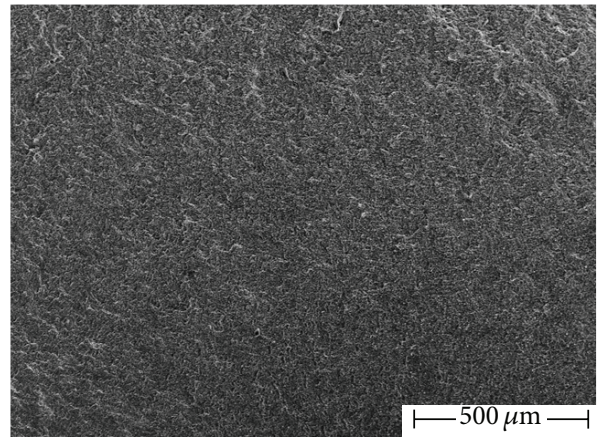

(c)

FIGURE 12: Stereo-images for the CG, FG, and UFG condition, respectively, for low stress amplitude.

cyclic loading [27]. It is noticed, as mentioned earlier in Table 4, that the ratio of endurance stress to yield strength decreases as the grain size is reduced.

\section{Conclusions}

The effects of RS as a SPD process and postdeformation heat treatments on the microstructure, mechanical properties, and fatigue performance of CP-Ti grade (1) are investigated and the following conclusions can be drawn out.

(1) UFG material can be produced by RS with average grain size of about $0.1 \mu \mathrm{m}$; FG and CG with average grain size of 0.36 and $90 \mu \mathrm{m}$, respectively, are produced by postdeformation annealing.

(2) Annealing the swaged sample at $450^{\circ} \mathrm{C}$ for $1 \mathrm{~h}$ has not changed the grain structure significantly.

(3) UFG material shows enhanced tensile and fatigue strength; on other hand, it has low tensile ductility and work-hardening capability. Work-hardening capability and ductility are achieved by postdeformation annealing, namely, in FG and CG materials. However, the annealing heat treatment resulted in a drop in static and fatigue strength of UFG material.

(4) The UFG material was highly fatigue notch sensitive ( $q=100 \%$ ), while the notch sensitivity for both FG and CG materials was $86 \%$ and $41 \%$, respectively.

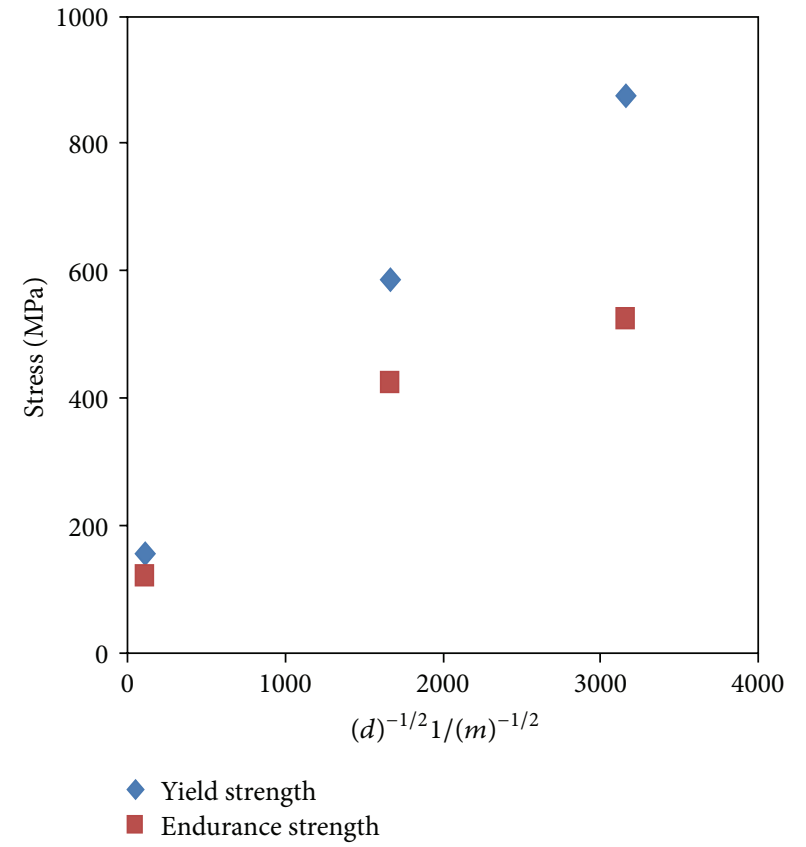

Figure 13: The grain size dependence of the endurance stress corresponding to $N=10^{7}$ load. Cycles and tensile yield stress for commercially pure titanium.

(5) Fatigue notch sensitivity in pure CP-Ti grade 1 can be closely correlated to the work-hardening capability 
and ductility; the higher work-hardening capability and ductility the lower fatigue notch sensitivity. This suggests that work-hardening capability and ductility have beneficial effects on suppressing the fatigue crack growth rate.

(6) The ratio of endurance strength to yield strength decreases as the grain size is reduced.

\section{Conflict of Interests}

The authors declare that there is no conflict of interests regarding the publication of this paper.

\section{Acknowledgments}

The first author would like to thank the German Academic Exchange Service (DAAD) for supporting his stay at TU Clausthal. The second author would like to acknowledge the partial support by Deanship of Scientific Research, College of Engineering, Research Centre, King Saud University.

\section{References}

[1] T. Sakai, M. Takeda, K. Shiozawa et al., "Experimental reconfirmation of characteristic $S-N$ property for high carbon chromium bearing steel in wide life region in rotating bending," Journal of the Society of Materials Science Japan, vol. 49, no. 7, pp. 779-785, 2000.

[2] M. Goto, T. Yamamoto, H. Nisitani, T. Sakai, and N. Kawagoishi, "Effect of removing surface hardened layer on the fatigue strength of bearing steel SUJ2 ground specimen in the long life field," Journal of the Society of Materials Science, Japan, vol. 49, no. 7, pp. 786-792, 2000.

[3] Y. Murakami, T. Nomoto, and T. Ueda, "On the mechanism of fatigue failure in the superlong life regime ( $\mathrm{N}>107$ cycles). Part I: influence of hydrogen trapped by inclusions," Fatigue and Fracture of Engineering Materials and Structures, vol. 23, no. 11, pp. 893-902, 2000.

[4] Y. Murakami, T. Nomoto, and T. Ueda, "On the mechanism of fatigue failure in the superlong life regime ( $N>10^{7}$ cycles). Part I: influence of hydrogen trapped by inclusions," Fatigue \& Fracture of Engineering Materials \& Structures, vol. 23, no. 11, pp. 893$902,2000$.

[5] Y. Murakami, N. N. Yokoyama, and J. Nagata, "Mechanism of fatigue failure in ultralong life regime," Fatigue and Fracture of Engineering Materials and Structures, vol. 25, no. 8-9, pp. 735$746,2002$.

[6] K. Shiozawa and L. Lu, "Very high-cycle fatigue behaviour of shot-peened high-carbon-chromium bearing steel," Fatigue and Fracture of Engineering Materials and Structures, vol. 25, no. 8-9, pp. 813-822, 2002.

[7] Y. Ochi, T. Matsumura, K. Masaki, and S. Yoshida, "Highcycle rotating bending fatigue property in very long-life regime of high-strength steels," Fatigue and Fracture of Engineering Materials and Structures, vol. 25, no. 8-9, pp. 823-830, 2002.

[8] T. Sakai, Y. Sato, and N. Oguma, "Characteristics S-N properties of high-carbon-chromium-bearing steel under axial loading in long-life fatigue," Fatigue and Fracture of Engineering Materials and Structures, vol. 25, no. 8-9, pp. 765-773, 2002.
[9] Y. Akiniwa, K. Tanaka, and H. Kimura, "Microstructural effects on crack closure and propagation thresholds of small fatigue cracks," Fatigue and Fracture of Engineering Materials and Structures, vol. 24, no. 12, pp. 817-830, 2001.

[10] S. R. Agnew, A. Y. Vinogradov, S. Hashimoto, and J. R. Weertman, "Overview of fatigue performance of $\mathrm{Cu}$ processed by severe plastic deformation," Journal of Electronic Materials, vol. 28, no. 9, pp. 1038-1044, 1999.

[11] H. Mughrabi and H. W. Höppel, "Cyclic deformation and fatigue properties of ultrafine grain size materials: current status and some criteria for improvement of the fatigue resistance," in Symposium B-Structure and Mechanical Properties of Nanophase Materials-Theory \& Computer Simulations vs. Experiment, vol. B2.1.1 of MRS Proceedings, p. 634, 2001.

[12] H. W. Höppel, M. Brunnbauer, H. Mughrabi, R. Z. Valiev, and A. P. Zhilyaev, "Cyclic deformation behaviour of ultrafine grain size copper produced by equal channel angular extrusion," in Proceedings of the Materials Week, Frankfurt, Germany, September 2000, http://www.materialsweek.org/proceedings.

[13] H. Mughrabi, H. W. Höppel, and M. Kautz, "Fatigue and microstructure of ultrafine-grained metals produced by severe plastic deformation," Scripta Materialia, vol. 51, no. 8, pp. 807812, 2004.

[14] E. Thiele, C. Holste, and R. Klemm, "Influence of size effect on microstructural changes in cyclically deformed polycrystalline nickel," Zeitschrift fuer Metallkunde, vol. 93, no. 7, pp. 730-736, 2002.

[15] E. Thiele, J. Bretschneider, C. Buque, N. Schell, A. Schwab, and C. Holste, "Internal strains in single grains of fatigued polycrystalline nickel," Materials Science Forum, vol. 404-407, pp. 823-828, 2002.

[16] H. W. Höppel, M. Kautz, C. Xu et al., "An overview: fatigue behaviour of ultrafine-grained metals and alloys," International Journal of Fatigue, vol. 28, no. 9, pp. 1001-1010, 2006.

[17] H. W. Höppel and R. Z. Valiev, "On the possibilities to enhance the fatigue properties of ultrafine-grained metals," Zeitschrift für Metallkunde, vol. 93, no. 7, pp. 641-648, 2002.

[18] A. Vinogradov and S. R. Agnew, "Nanocrystalline materials: fatigue," in Dekker Encyclopedia of Nanoscience and Nanotechnology, pp. 2269-2288, 2004.

[19] F. Ebrahimi, G. R. Bourne, M. S. Kelly, and T. E. Matthews, "Mechanical properties of nanocrystalline nickel produced by electrodeposition," Nanostructured Materials, vol. 11, no. 3, pp. 343-350, 1999.

[20] G. D. Hughes, S. D. Smith, C. S. Pande, H. R. Johnson, and R. W. Armstrong, "Hall-petch strengthening for the microhardness of twelve nanometer grain diameter electrodeposited nickel," Scripta Metallurgica, vol. 20, no. 1, pp. 93-97, 1986.

[21] J. S. C. Jang and C. C. Koch, "The Hall-Petch relationship in nanocrystalline iron produced by ball milling," Scripta Metallurgica et Materialia, vol. 24, no. 8, pp. 1599-1604, 1990.

[22] F. Dalla Torre, H. Van Swygenhoven, and M. Victoria, "Nanocrystalline electrodeposited Ni: microstructure and tensile properties," Acta Materialia, vol. 50, no. 15, pp. 3957-3970, 2002.

[23] M. S. Soliman, E. A. El-Danaf, and A. A. Almajid, "Enhancement of static and fatigue strength of $1050 \mathrm{Al}$ processed by equal-channel angular pressing using two routes," Materials Science and Engineering A, vol. 532, pp. 120-129, 2012.

[24] P. Lukáš, L. Kunz, L. Navrátilová, and O. Bokůvka, "Fatigue damage of ultrafine-grain copper in very-high cycle fatigue 
region," Materials Science and Engineering A, vol. 528, no. 2223, pp. 7036-7040, 2011.

[25] G. E. Dieter, Mechanical Metallurgy, McGraw-Hill Series in Materials Science and Engineering, McGraw-Hill, 3rd edition, 1961.

[26] J. D. Eshelby, F. C. Frank, and F. R. Nabarro, "The equilibrium of linear arrays of dislocations," Philosophical Magazine, vol. 42, pp. 351-364, 1951.

[27] R. W. Armstrong, "60 years of hall-petch: past to present nanoscale connections," Materials Transactions, vol. 55, no. 1, pp. 2$12,2014$.

[28] R. V. Mises, "Mechanik der plastischen Formänderung von Kristallen," Zeitschrift für Angewandte Mathematik und Mechanik, vol. 8, no. 3, pp. 161-185, 1928.

[29] H. Neuber, Theory of Notch Stresses, Navy Department, David Taylor Model Basin, Washington, DC, USA, 1945.

[30] M. Wollmann, M. Mhaede, J. Atoura, and L. Wagner, "Influence of mechanical surface treatments on notched fatigue of various titanium alloys," in Proceedings of the 12th World Conference on Titanium (Ti '11), vol. 2, pp. 972-975, June 2011.

[31] Torrington-Machinery, 2012, http://www.torrington-machinery.com/images/pic_rotary_swagingl.gif.

[32] Shahzad, Influence of extrusion parameters on microstructure development and mechanical properties in wrought magnesium alloys AZ80 and ZK60, Dr.-Ing [Ph.D. thesis], TU Clausthal, 2007.

[33] E. A. El-Danaf, "Texture evolution and fraction of favorably oriented fibers in commercially pure aluminum processed to 16 ECAP passes," Materials Science and Engineering A, vol. 492, no. 1-2, pp. 141-152, 2008.

[34] E. A. El-Danaf, M. M. El-Rayes, and M. S. Soliman, "Friction stir processing: an effective technique to refine grain structure and enhance ductility," Materials and Design, vol. 31, no. 3, pp. 1231-1236, 2010.

[35] E. El-Danaf, M. Kawasaki, M. El-Rayes, M. Baig, J. A. Mohammed, and T. G. Langdon, "Mechanical properties and microstructure evolution in an aluminum 6082 alloy processed by high-pressure torsion," Journal of Materials Science, vol. 49, no. 19, pp. 6597-6607, 2014.

[36] M. A. Abdulstaar, E. A. El-Danaf, N. S. Waluyo, and L. Wagner, "Severe plastic deformation of commercial purity aluminum by rotary swaging: microstructure evolution and mechanical properties," Materials Science \& Engineering A, vol. 565, pp. 351$358,2013$.

[37] H. ALkhazraji, E. El-Danaf, M. Wollmann, and L. Wagner, "Microstructure, mechanical and fatigue strength of Ti54 M processed by rotary swaging," Journal of Materials Engineering and Performance. In press.

[38] H. ALkhazraji, Z. Mohammed, Z. Zhong et al., "Estimation of dislocation density in cold-rolled commercially pure titanium by using synchrotron diffraction," Metallurgical and Materials Transactions B, vol. 45, no. 4, pp. 1557-1564, 2014.

[39] P. Lukáš, L. Kunz, and M. Svoboda, "Fatigue notch sensitivity of ultrafine-grained copper," Materials Science and Engineering: A, vol. 391, no. 1-2, pp. 337-341, 2005.

[40] W.-J. Kim, C.-Y. Hyun, and H.-K. Kim, "Fatigue strength of ultrafine-grained pure Ti after severe plastic deformation," Scripta Materialia, vol. 54, no. 10, pp. 1745-1750, 2006.

[41] I. P. Semenova, G. K. Salimgareeva, V. V. Latysh, T. Lowe, and R. Z. Valiev, "Enhanced fatigue strength of commercially pure $\mathrm{Ti}$ processed by severe plastic deformation," Materials Science and Engineering A, vol. 503, no. 1-2, pp. 92-95, 2009.
[42] H. W. Höppel, Z. M. Zhou, H. Mughrabi, and R. Z. Valiev, "Microstructural study of the parameters governing coarsening and cyclic softening in fatigued ultrafine-grained copper," Philosophical Magazine A: Physics of Condensed Matter, Structure, Defects and Mechanical Properties, vol. 82, no. 9, pp. 1781-1794, 2002.

[43] H. W. Höppel, H. Mughrabi, and A. Vinogradov, "Fatigue properties of bulk nanostructured materials," in Bulk Nanostructured Materials, M. Zehetbauer and Y. T. Zhu, Eds., Wiley-VCH, Weinheim, Germany, 2008.

[44] A. Vinogradov and S. Agnew, "Nanocrystalline materials: fatigue," in Dekker Encyclopedia of Nanoscience and Nanotechnology, J. A. Schwarz, C. Contescu, and K. Putyera, Eds., pp. 2269-2288, Marcel Dekker, New York, NY, USA, 2004.

[45] Y. Estrin and A. Vinogradov, "Fatigue behaviour of light alloys with ultrafine grain structure produced by severe plastic deformation: an overview," International Journal of Fatigue, vol. 32, no. 6, pp. 898-907, 2010.

[46] A. A. S. Mohammed, E. A. El-Danaf, and A. A. Radwan, "A criterion for shear banding localization in polycrystalline FCC metals and alloys and critical working conditions for different microstructural variables," Journal of Materials Processing Technology, vol. 186, no. 1-3, pp. 14-21, 2007.

[47] B. S. Altan, Severe Plastic Deformation: Toward Bulk Production of Nanostructured Materials, Nova, New York, NY, USA, 2006.

[48] A. K. Head, "The positions of dislocations in arrays," Philosophical Magazine, vol. 4, no. 39, pp. 295-302, 1959.

[49] E. O. Hall, "The deformation and ageing of mild steel: III. Discussion of results," Proceedings of the Physical Society. Section $B$, vol. 64, no. 9, pp. 747-753, 1951.

[50] N. J. Petch, "The cleavage strength of polycrystals," Journal of the Iron and Steel Institute, vol. 174, pp. 25-28, 1953. 

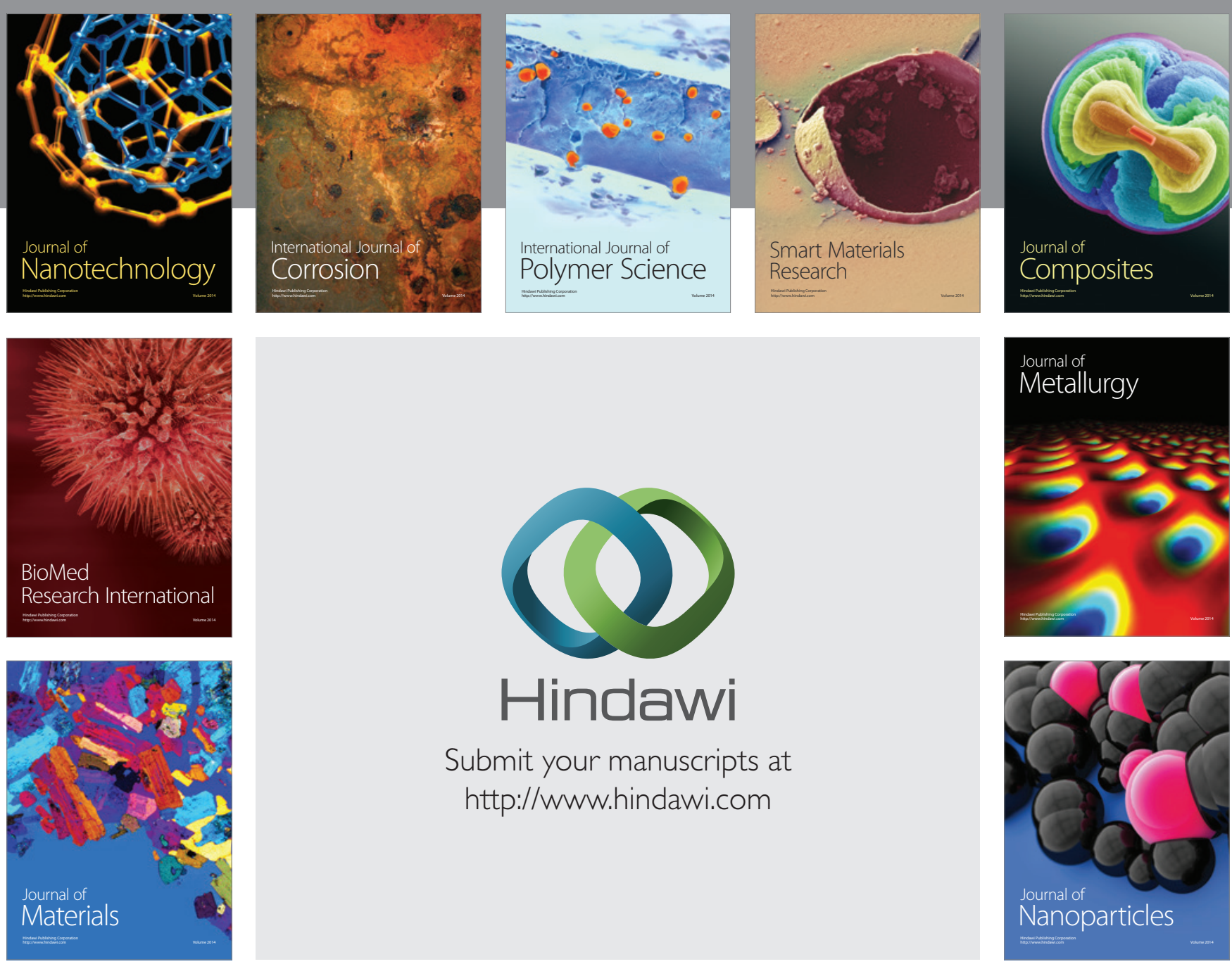

Submit your manuscripts at http://www.hindawi.com
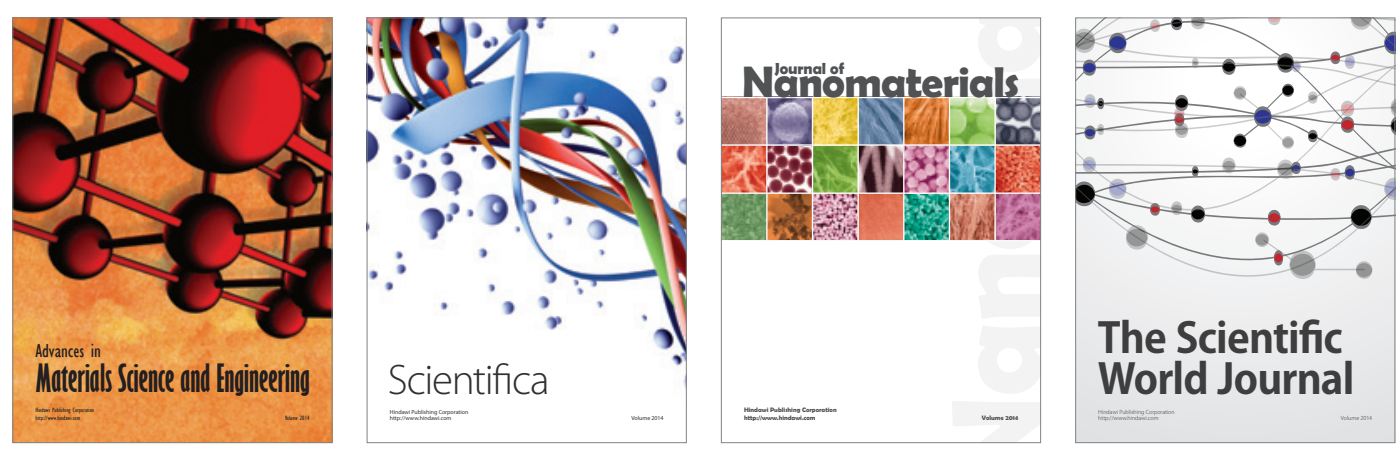

\section{The Scientific World Journal}
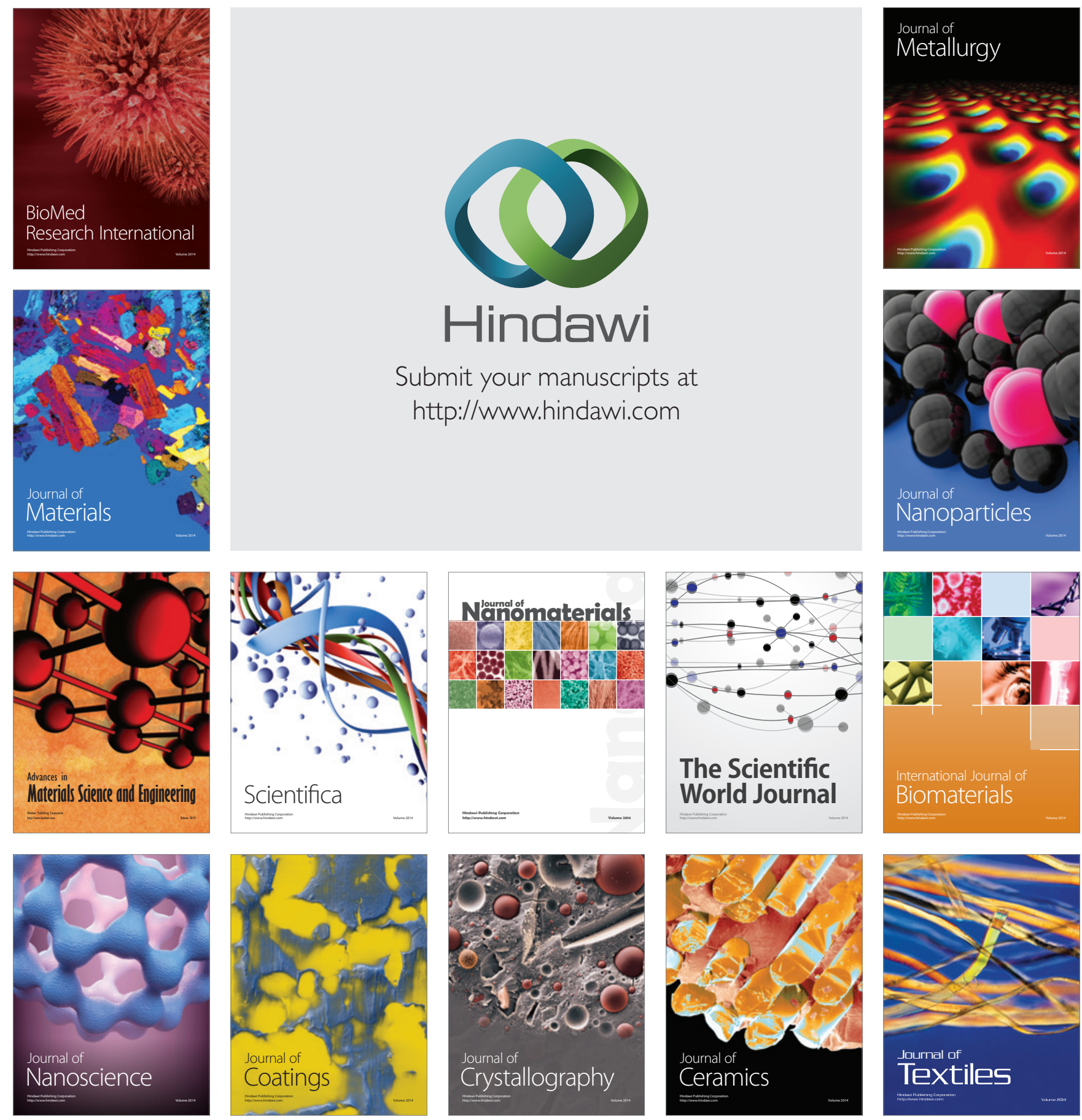